\title{
Prognostic value of dobutamine stress cardiovascular magnetic resonance in patients with previous coronary revascularization
}

\author{
Sebastian Kelle*, Rolf Gebker, Amedeo Chiribiri, Juliane Vierecke, Christina Egnell, Ernst Wellnhofer, Christoph Klein, \\ Eckart Fleck
}

From 2011 SCMR/Euro CMR Joint Scientific Sessions

Nice, France. 3-6 February 2011

\section{Introduction}

The aim of this study was to assess the prognostic value of dobutamine stress cardiovascular magnetic resonance (DCMR) in patients with previous myocardial revascularization. The role of DCMR in the risk stratification of patients with previous coronary revascularization has not been well defined.

\section{Methods}

Clinical data and DCMR results were analyzed in 687 consecutive patients with previous percutaneous or surgical coronary revascularisation undergoing DCMR between 2000 and 2004. Follow up was successful for 654 (95.2\%) patients. Two hundred and nineteen patients who underwent early revascularisation ( $\leq 3$ months) after the test were excluded from analysis. The remaining 435 patients (median age, 64 years) were followed up for a mean of $37 \pm 18$ months. WMA at rest and the presence of stress-induced WMA (ischemia) were assessed for each patient. Cox proportional hazards regression models were used to identify independent predictors of the composite of cardiac events defined as cardiac death and non-fatal myocardial infarction.

\section{Results}

Thirty four cardiac events were reported, documented cardiac death in twenty six and non-fatal myocardial infarction in eight patients. In multivariate analysis of clinical data, independent predictors of late cardiac events were the number of dysfunctional segments at rest (hazard ratio (HR) 1.2; 95\% confidence interval (CI)

German Heart Institute Berlin, Berlin, Germany

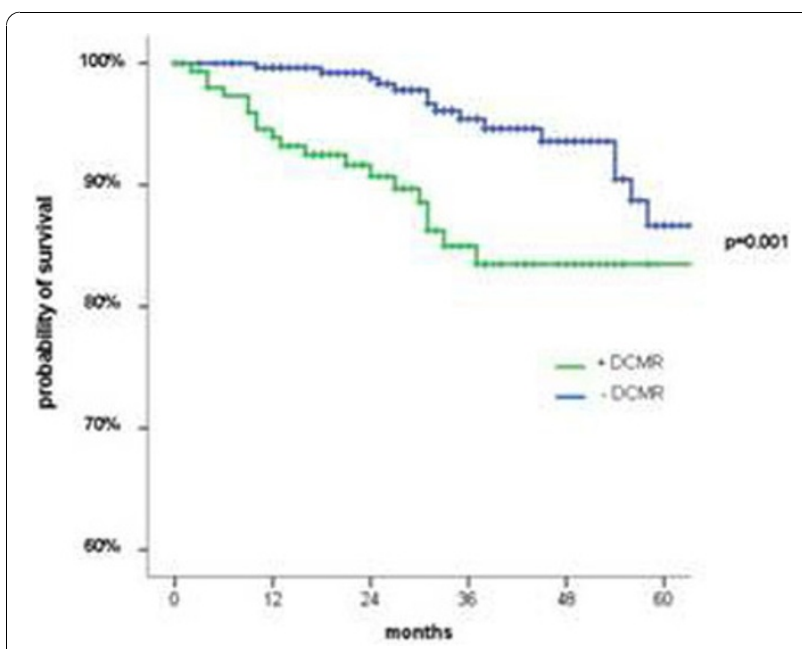

Figure 1 Kaplan-Meier survival curves of patients with previous coronary revascularization with normal and positive DCMR.

1.1 to $1.3 ; \mathrm{p}<0.001)$ and stress-induced WMA on DCMR (HR 2.9, 95\% CI 1.5 to 5.8; $\mathrm{p}=0.002$ ). (Figure 1).

\section{Conclusions}

Myocardial ischaemia during DCMR is independently predictive of cardiac events among patients with previous myocardial revascularisation.

Published: 2 February 2011
doi:10.1186/1532-429X-13-S1-P165

Cite this article as: Kelle et al:: Prognostic value of dobutamine stress cardiovascular magnetic resonance in patients with previous coronary revascularization. Journal of Cardiovascular Magnetic Resonance 201113 (Suppl 1):P165.

(c) 2011 Kelle et al; licensee BioMed Central Ltd. This is an open access article distributed under the terms of the Creative Commons 